\title{
Ephemeride für die Wiederkehr des Faye'schen Cometen.
}

Für den Faye'schen Cometen habe ich aus den von Prof. Möller im Berl. Astr. Jahrb. für I 882 gegebenen Elementen ohne Rücksicht auf die Störungen und mit Annahme $T_{0}=1896$ März r 4.7 die folgende Aufsuchungsephemeride berechnet.

I $2^{\text {h }}$ M. Z. Berlin.

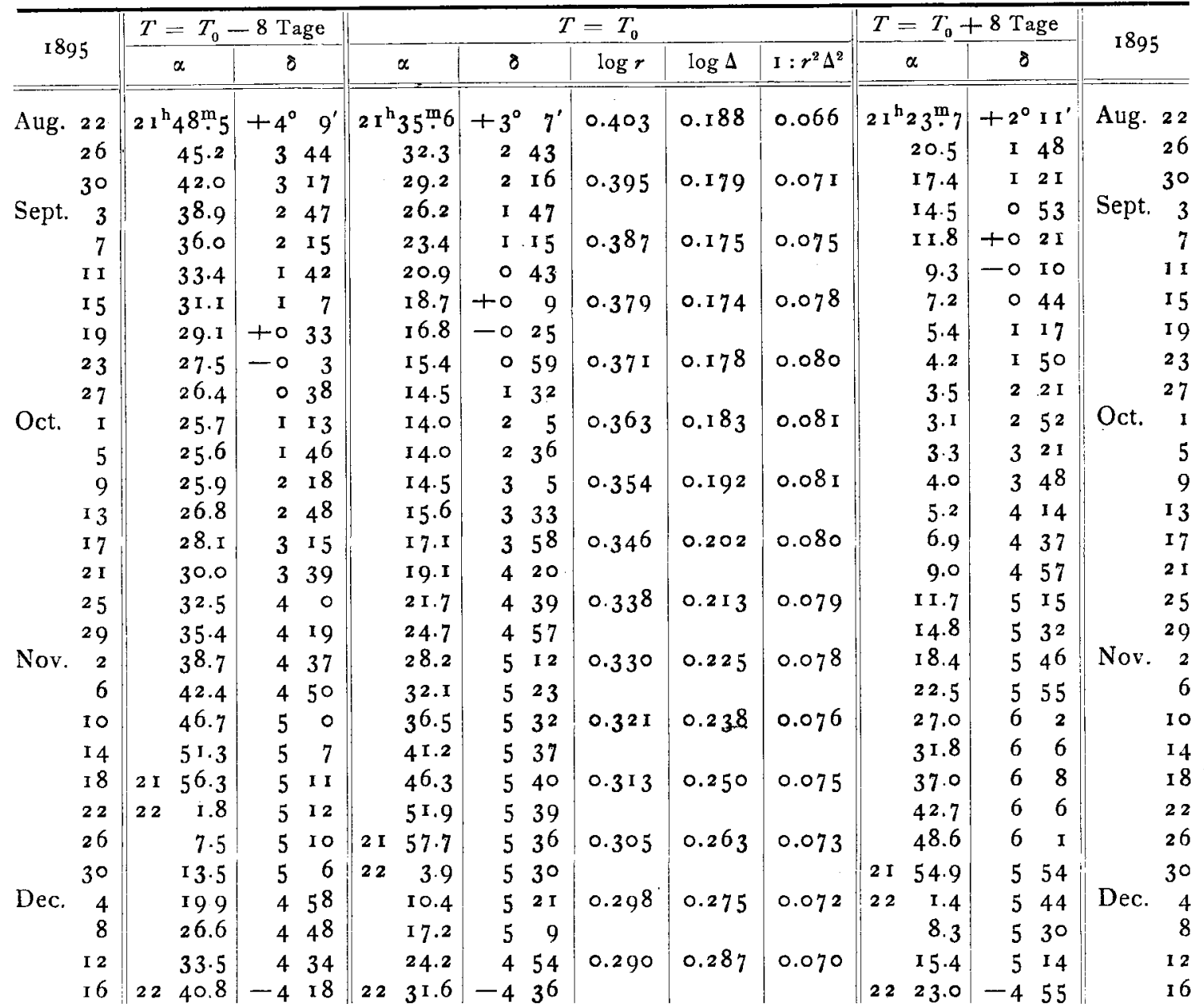

Lund I 895 Aug. I 9 .

Folke Engström.

\section{Beobachtung der Bedeckung des Regulus durch den Mond 1895 Juni 26.}

Die Regulus-Bedeckung vom 26. Juni d. J. habe ich wie folgt beobachtet:

Das plötzliche Verlöschen des Sterns erfolgte nach unserem Chronometer um $9^{\mathrm{h}} \mathrm{I} 7^{\mathrm{m}} 23^{\mathrm{s}}$ M. E. Z., jedoch nahm ich $11^{\mathrm{s}}$ vorher eine zwar schwache, aber immerhin ganz unzweifelhafte Lichtschwächung wahr, die wohl kaum in der Bedeckung des vorangehenden Theiles der Diffractionsringe ihre Erklärung finden kann, sondern eher auf einen ganz nahen Begleiter hindeuten dürfte.

Manora Sternwarte, Lussinpiccolo, Istrien, 1895 Juli 8.

Leo Brenner.

\section{Inhalt:}

Zn Nr. 3306. F. G. Hagen. Ueber einen möglichen systematischen Fehler des Zenithteleskops. 289. - Zusatz hierzu, 295. - H. Battermann. Beobachtung der Plejadenbedeckung 1895 Juli 17 auf der Kgl. Sternwarte in Berlin. 297. - W. Doberck. Radiants of ShootingStars. 299. - F. Engström. Ephemeride für die Wiederkehr des Faye'schen Cometen. 303. - L. Brenner. Beobachtung der Bedeckung des Regulus durch den Mond I895 Juni 26. 303. 